\title{
My Values
}

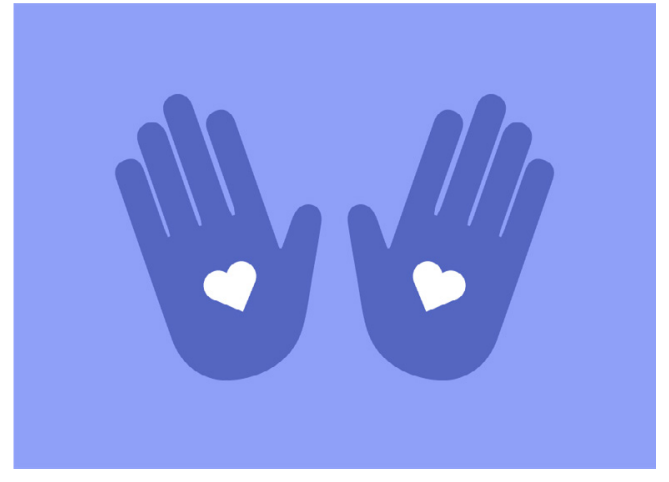

PAGE 1: Overview

PAGE 2: Activity

PAGE 3: Example

\section{How long does it take?}

15 minutes

\section{How do I do it?}

First, identify 2-3 values, then write about why they are important to you.

\section{How does it work?}

By reflecting on your values in writing, you can affirm your identity and self-worth, creating a virtuous cycle of confidence, effort, and achievement.

Inspired by: Cohen, G. L., \& Sherman, D. K. (2014). The psychology of change: self-affirmation and social psychological intervention. Annual Review of Psychology, 65, 333-371.

"If only I can be myself, I'll be satisfied." 


\section{My Values}

\section{Character LAB}

Read this list of values and think about each one. Circle 2 to 3 that are most important to you.

- Athletic ability

- Art and literature

- Creativity, discovering, or inventing things to make a difference in the world

- Independence

- Kindness and generosity
- Living in the moment

- Membership in a social group (such as your community, racial group, or school club)

- Music

- My community

- My moral principles
- Nature and the environment

- Relationships with friends and family

- Sense of humor

- Success in my career

- Other:

In a few sentences, describe why the selected values are important to you. Focus on your thoughts and feelings, and don't worry about spelling, grammar, or how well-written it is. 


\section{My Values}

\section{Character LAB}

\section{EXAMPLE}

Read this list of values and think about each one. Circle 2 to 3 that are most important to you.

- Athletic ability

- Art and literature

- Creativity, discovering, or inventing things to make a difference in the world

- Independence

- Kindness and generosity
- Living in the moment

- Membership in a social group (such as your community, racial group, or school club)

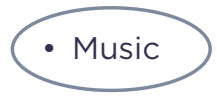

- My community

- My moral principles
- Nature and the environment

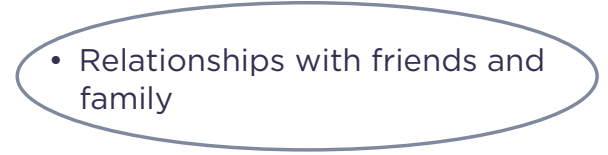

- Sense of humor

- Success in my career

- Other:

Clear first value

In a few sentences, describe why the selected values are important to you. Focus on your thoughts and feelings, and don't worry about spelling, grammar, or how well-written it is.

My relationships with my friends and family are important to me because they make me who I am. My mom taught me so many important things about how to be kind and how to make my favorite foods and how to be brave. My sister and I fight sometimes but she always has my back and makes sure I laugh when I am in a mood. Clear second value ( stories of personal significance (

Music is also important to me. When I listen to music, I can be somewhere totally different. My favorite songs make me feel better even when Im totally messed up. Listening to music with my friends is my favorite thing to do. ( gives multiple details about value 